\title{
Changing Male Preferences for Female Body Type in the US: An Adaptive Response to a Changing Socioeconomic Climate
}

\author{
Denis K. Deady, Miriam J. Law Smith* \\ Department of Psychology, University of Limerick, Limerick, Ireland \\ Email: "miriam.lawsmith@ul.ie
}

Received 9 November 2015; accepted 18 December 2015; published 22 December 2015

Copyright (C) 2015 by authors and Scientific Research Publishing Inc.

This work is licensed under the Creative Commons Attribution International License (CC BY). http://creativecommons.org/licenses/by/4.0/

c) (7) Open Access

\begin{abstract}
The debate over changing ideals of beauty in Western society remains unresolved more than 20 years after Singh's (1993) seminal study [1] suggesting there was a universal male preference for a female body shape with a low waist to hip ratio (circa 0.7 ), which relates to maximum fecundity. Subsequent research has supported this universal preference while other studies have found that male preferences may be context dependent and capable of calibrating in response to the specific selection pressures of differing socio-ecologies. The current paper aims to help resolve this uncertainty with an analysis of body measurements of female models who were Playboy centrefolds from 1953-2014. Height is shown to increase significantly over time (beyond a level that could be attributed to a positive secular trend). Along with a significant increase in waist to hip ratio (WHR) (i.e. more tubular) and a significant decrease in Body Mass Index (BMI), these results represent a shift in male preferences away from signals of maximum fecundity, and towards a more androgenic female body shape. Contemporary research indicates that increasing height in women is positively associated with career orientation and negatively with reproduction ambition, thus the change in Western male preferences may be interpreted as an adaptive response to ecological conditions where a smaller family size and greater involvement of female partners in resource acquisition is adaptive.
\end{abstract}

\section{Keywords}

Female Body Shape, Male Preferences, Behavioural Science

\section{Introduction}

Extensive cross cultural evolutionary behavioural science research indicates that males and females differ in

${ }^{*}$ Corresponding author.

How to cite this paper: Deady, D.K. and Law Smith, M.J. (2015) Changing Male Preferences for Female Body Type in the US: An Adaptive Response to a Changing Socioeconomic Climate. Journal of Behavioral and Brain Science, 5, 570-577. 
their criteria for selecting a potential mate. Females tend to place a higher importance on resource acquisition potential in a prospective partner, while males prefer traits that signal high reproductive capacity [2]. These preferences are thought to be adaptive and related to maximising reproductive success, with males favouring traits such as low waist to hip ratio (WHR) and moderate body mass index (BMI), both which have been found to be markers of health, youth and fecundity [3]-[5]. Women with low WHRs $(\lessgtr 0.7)$ have more regular menstrual [6] and ovulation [7] cycles, are more fecund as signalled by higher levels of the fertility hormones 17- $\beta$ oestradiol and progesterone [3], have better changes of conceiving via both artificial insemination [4] and in vitro embryo fertilization transfer [8], and show improved fetal brain development in pregnancy [9]. Higher WHRs are associated with higher testosterone and cortisol and lower estrogen levels [10] [11]. WHR is also strongly associated with general health; with high ratios associated with increased susceptibility to heart, gallbladder and kidney diseases, stroke, various forms of cancer [12]-[14], diabetes [15] and early mortality [16]. Female BMI (weight in $\mathrm{kg}$ /height in $\mathrm{m}^{2}$ ) of approximately 18 - 21 has been shown to be favoured by males [5] and is also associated with improved fecundity [17], health and mortality [18].

Due to these health and fertility benefits associated with a low WHR and moderate BMI in women, it is not surprising (from an evolutionary perspective) that men tend to exhibit a preference for this female body type (often referred to as an "hourglass" shape) [19]. Although a preference for the "hourglass" archetype has been shown to be relatively consistent across different cultures, nevertheless, small but significant differences in male preferences have been revealed [20]-[30]. It has been postulated that male preference is moulded by selection pressures to be conditional; and that preference is capable of calibrating to local socio-ecological conditions and their associated selection pressures [31]-[34]. In environments with a pressure for maximal fertility, a lower WHR and thus maximum fecundity may be favoured. However, in environments of resource scarcity, such as that inhabited by the Zulu foragers of South Africa, plumpness and a high BMI are preferred by males and these traits are also related to improved health and fertility. Also, it has been hypothesized that in societies where there are fitness advantages for females to be more engaged in resource competition, such as the Hadza and Shiwiar foragers and the modern Western society, there may emerge a selection pressure to favour the higher WHR of more androgenic females and their associated traits of increased competitiveness and assertiveness [33] [34].

Western society has seen significantly more females involved in resource competition over the last 60 years. Fifty-seven percent of females participated in the labour force in the US in 2012 compared to only 32\% in 1948 [35]. Forty percent of US households had a female breadwinner in 2011 compared to only $11 \%$ in 1960 [36]. The increased educational costs of raising children who are capable of successfully competing in the modern Western workforce [37] has resulted in fitness advantages of dual parent incomes and smaller family size where parental investment can be more strongly concentrated on fewer children [38]. Thus fertility has been traded off for increased investment in fewer offspring and this adaptation is to a large part reliant on both parents being involved in resource acquisition (i.e. dual income households). With the greater involvement of females in resource competition, it begs the questions: has there been an accompanying shift in male preference for a more androgenic female body type that signals a greater capacity for resource acquisition?

Although research has previously looked at whether men's preferences for female body shape have changed during this time period, results to date have been conflicting. The seminal study analysed WHRs of US Playboy playmates and Miss America winners between the years 1959 and 1990 and found that males remained consistent in their preference for a WHR ratio of 0.7 [1]. A subsequent study focusing on US playmates from 1978 to 1998 also found that WHR and BMI preferences remained constant over time [39]. However, research has also shown that British fashion models over the period 1967 to 1987 showed a trend towards a more "tubular" or androgenic body shape [40] and there is also evidence that male preferences for US playmates and Miss America winners have changed to favour a higher WHR and more androgenic body shape [41]-[44].

The present study aims to resolve whether there has been a change in male preferences towards a more androgenic female body in Western society, as might be predicted by Cashdan's androgen/estrogen trade off hypothesis [33]. This study will look at US playmate centrefolds between December 1953 and December 2014, but unlike the seminal Singh study [1], the complete database will be utilised and a longer historical time period will be analysed. As well as looking at WHR and BMI, this study will also analyse height data. Research clearly shows that height is significantly influenced by androgens; their growth promoting effect on bones from puberty onwards explains why adult males are taller than adult females across cultures [45]-[47]. Therefore it is not surprising that taller females tend to possess more stereotypically masculine personality traits. For example, taller females (of reproductive age) have been found to desire fewer children, and put greater importance on having a 
career and also tend to be more competitive in their careers than shorter women [48]. Similarly, post reproductive aged taller females have been found to have fewer children and are more career orientated [48]. If there has been a shift in preference towards a female body type that signals greater capacity for resource acquisition then one would expect to see playmates getting taller over time as well as showing a higher WHR.

\section{Methods}

Anthropometric data on the 725 US Playboy centrefolds from December 1953 to December 2014 (age range: 17 - 33 years old, mean $=22, \mathrm{SD}=2$ ) was collected using the official US Playboy Playmate database (www.playboy.com). Weight, height, waist circumference and hip circumference measurements for each centrefold model were collated from the database. Complete data was not available for each of the 725 centrefolds (e.g. height data, $\mathrm{n}=$ 691). Composite measures were then calculated from this data: Waist to Hip Ratio (WHR), and Body Mass Index (BMI) (weight in $\mathrm{kg} /$ height in $\mathrm{m}^{2}$ ). Height, BMI, and WHR measures were correlated against time (magazine issue numbers) with Pearson's r correlation tests using SPSS v 22.0.

Bust to Waist ratio has not been analysed in the current study, as the data available on the playmates contains inconsistent bust measurements. Many of the playmates stats are listed as overall bust measurement (i.e. traditional tape measure circumference around body at the nipple line), while others are listed as bra size measurement (i.e. rib cage circumference plus cup size). Although bra size measurements could be converted relatively accurately to overall bust measurement, the stats with only the bust measurement cannot be converted back to bra size. Bra size would be the most valid measurement for a femininity metric as it a measure of breast size, whereas the bust measurement alone cannot give details of breast size (as the circumference measurement can consist of varying measures of back width, breast bone, and muscle, along with breast tissue size). This is a limitation of previous studies that have not considered this confound in their use of bust measurement as a femininity metric.

As there has been a secular positive trend in height in general over time that is largely attributable to improved nutrition [49], it is important to not only correlate height with time, but to analyse whether there had been an increase in height of centrefolds that was significantly greater that the population secular trend.

US national height data was obtained from a Centre for Disease Control (CDC) report on national US height trends from 1960 to 2002 [49]. Data was available on females aged 20 - 29 years old for the time interval 1960 to 1962 and also for the period 1999 to 2002. In order to perform a valid comparison, females under the age of 19 were removed from the 1960-62 playmate cohort $(n=13)$ and the 1999-2002 cohort $(n=5)$. There were no females over the age of 29 in either cohort. This left $\mathrm{N}=22$ for 1960-62 playmate cohort and $\mathrm{N}=43$ for the 1999-02 playmate cohort. One sample T-tests were employed to determine if there was a change in playmate height between earlier and later historical intervals that could not be explained by an underlying secular change.

\section{Results}

WHR, and height increased significantly over time: $[\mathrm{r}=0.53, \mathrm{n}=689, \mathrm{p}=<0.001$, see Figure 1$]$ and $[\mathrm{r}=0.31$, $\mathrm{n}=691, \mathrm{p}<0.001$, see Figure 2] respectively, with BMI showing a significant decrease $[\mathrm{r}=-0.31, \mathrm{n}=684, \mathrm{p}<$ 0.001 , see Figure 3]. A one sample t-test showed no difference between playmate height and the national female mean for the 1960 to 1962 interval [t(21) $=1.544, \mathrm{p}=0.137$ ]. However, playmates were significantly taller than the national mean for the 1999 to 2002 interval [t(42) $=7.32, \mathrm{p}<0.001$, see Figure 4].

\section{Discussion}

The current study's analysis of anthropometric data of US Playmate centrefolds from 1953-2014 revealed significant shifts in body measurements over time. BMI significantly decreased over time, height significantly increased (at a level significantly greater than the secular trend for increasing height), and WHR increased significantly. WHR preference shifted away from maximum fecundity and towards a more tubular androgenic form, BMI moved towards the lower end of the optimal fecundity range, and the increase in height also showed a shift in preference towards a more androgenic body type.

The results of the study clearly demonstrate a shift in preference away from a body type that signals maximum fecundity and towards a type that signals a higher androgen profile and increased capability in resource competition. The results support the hypothesis that mate preferences can be context dependent and calibrates 


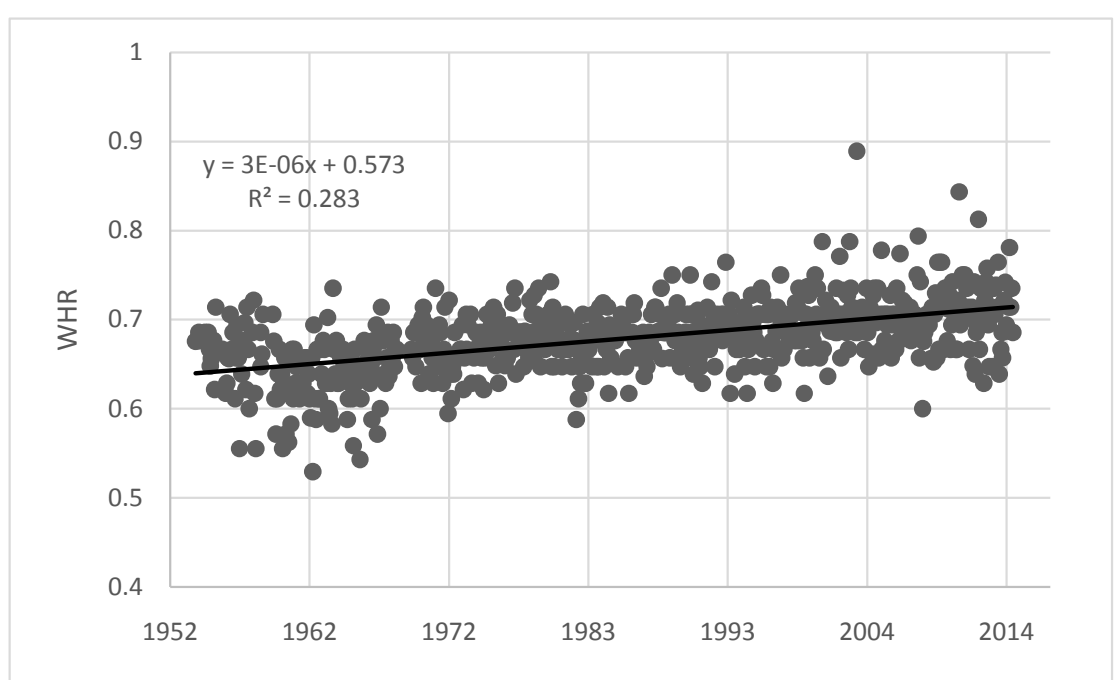

Figure 1.WHRs of Playboy centrefolds from Dec 1953 to Dec 2014 ( $\mathrm{N}=689)$.

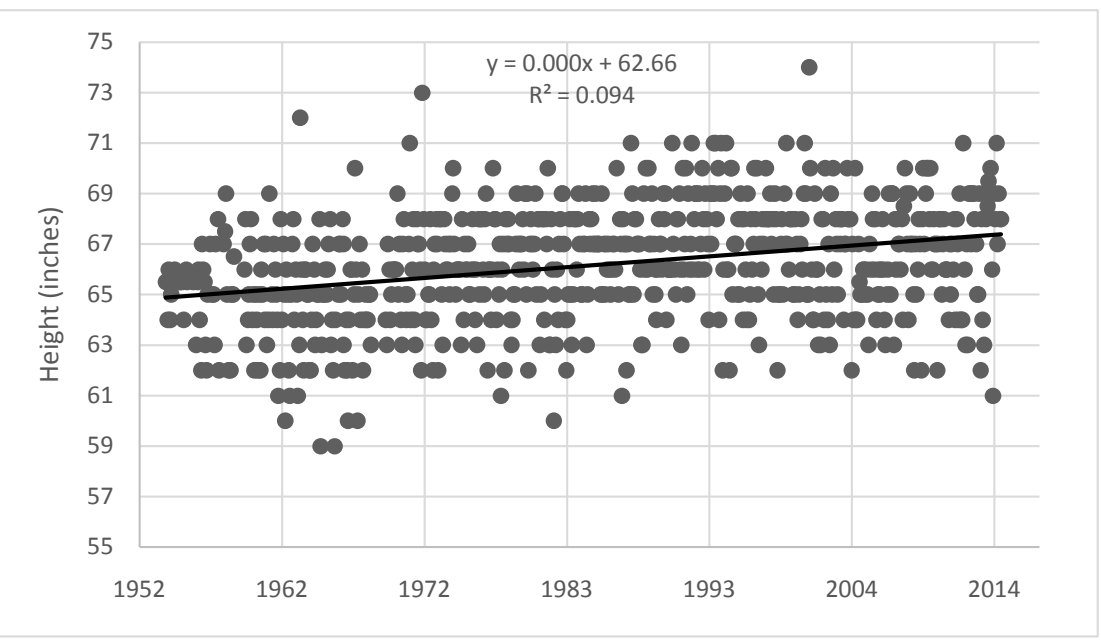

Figure 2. Height (inches) of Playboy centrefolds from Dec 1953 to Dec 2014 (N = 691).

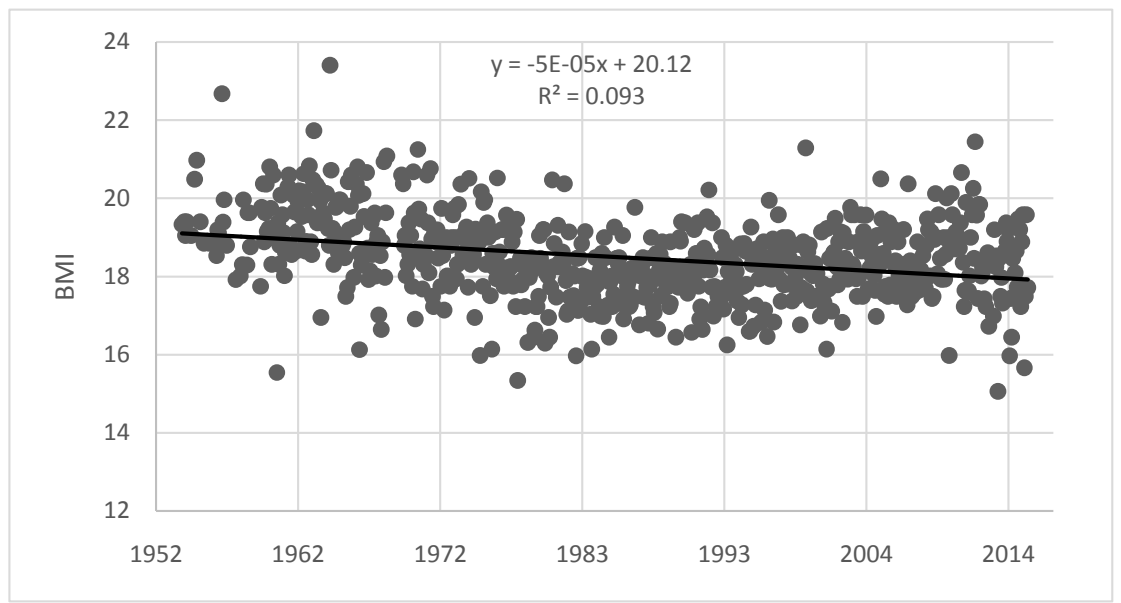

Figure 3. BMIs of Playboy centrefolds from Dec 1953 to Dec 2014 (N = 684). 


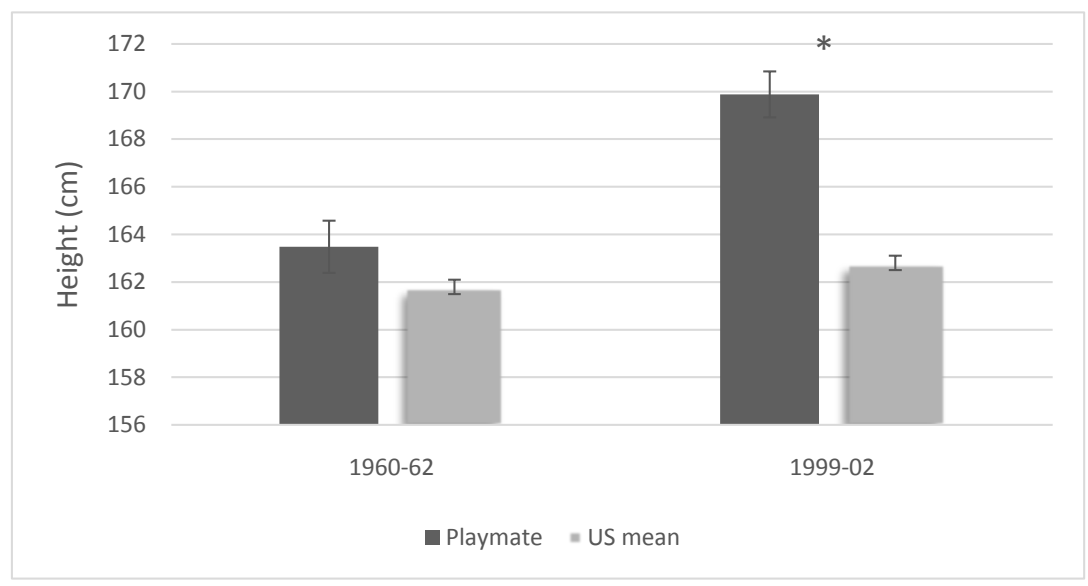

Figure 4. Height of playmates versus US national means for females aged 20 - 29 years. Comparing 1960 to 1962 versus 1999 to 2002. *Highly significant difference $(\mathrm{p}<0.001)$.

towards traits that confer a fitness advantage in a particular socio-ecology [31]. This current study results of a significant shift in male preferences may represent an adaptive strategy where maximum fecundity is being traded off for resource acquisition capability (in line with Cashdan's [33] androgen/estrogen trade-off hypothesis) in response to a socio-economic environment that necessitates dual-parent incomes and smaller family size (e.g. [38]). This explanation for the striking shift in preference for taller females is supported by research showing that taller females rate themselves as more competitive at work, and place greater importance on having a career, whilst also rating themselves as less "broody" and desiring fewer children than shorter females (e.g. [48]), and that these personality traits are related to underlying testosterone levels (e.g. in women [50]; and in men [51]) and underlying oestrogen levels in women [52]. Men also rate taller women as more ambitious and assertive but less nurturing and "homely" than shorter women [53]. Comparable supporting evidence is also available for explaining the shift in male preference towards a higher WHR; as women with higher androgenic profiles display personality characteristics which favour success in resource competition [33].

A limitation of the current and previous studies might be that the US Playboy centrefold models are assumed to represent typical male preferences for female body types across the 60 year time period. Future studies could seek to corroborate this demonstrated male preference shift by using different available US model datasets across the same time period, and also across other countries that share the similar Western culture (e.g. UK and European countries).

The current study demonstrates a systematic and significant shift over 60 years in US male preferences for female body type; as manifested by US Playboy centrefold models, towards a more androgenic body type which signals greater resource competitiveness and reduced reproductive ambition. This may represent an adaptive response to a changing socio-economic environment which necessitates smaller family size and dual-parent income.

\section{References}

[1] Singh, D. (1993) Adaptive Significance of Female Physical Attractiveness: Role of Waist-to-Hip Ratio. Journal of Personality and Social Psychology, 65, 293-307. http://dx.doi.org/10.1037/0022-3514.65.2.293

[2] Buss, D. (1989) Sex Differences in Human Mate Preferences: Evolutionary Hypotheses Tested in 37 Cultures. Behavioral and Brain Sciences, 12, 1-14. http://dx.doi.org/10.1017/S0140525X00023992

[3] Jasieńska, G., Ziomkiewicz, A., Ellison, P.T., Lipson, S.F. and Thune, I. (2004) Large Breasts and Narrow Waists Indicate High Reproductive Potential in Women. Proceedings of the Royal Society: Biological Sciences, 271, 1213-1217. http://dx.doi.org/10.1098/rspb.2004.2712

[4] Zaadstra, B.M., Seidell, J.C. and Van Noord, P.A., te Velde, E.R., Habbema, J.D., Vrieswijk, B. and Karbaat, J. (1993) Fat and Female Fecundity: Prospective Study of Effect of Body Fat Distribution on Conception Rates. BMJ, 306, 484-487. http://dx.doi.org/10.1136/bmj.306.6876.484

[5] Tovée, M.J., Reinhardt, S., Emery, J.L. and Cornelissen, P.L. (1998) Optimum Body-Mass Index and Maximum Sex- 
ual Attractiveness. Lancet, 352, 548. http://dx.doi.org/10.1016/S0140-6736(05)79257-6

[6] van Hooff, M.H., Voorhorst, F.J., Kaptein, M.B., Hirasing, R.A., Koppenaal, C. and Schoemaker, J. (2000) Polycystic Ovaries in Adolescents and the Relationship with Menstrual Cycle Patterns, Luteinizing Hormone, Androgens, and Insulin. Fertility and Sterility, 74, 49-58. http://dx.doi.org/10.1016/S0015-0282(00)00584-7

[7] Morán, C., Hernández, E., Ruíz, J.E., Fonseca, M.E., Bermúdez, J.A. and Zárate, A. (1999) Upper Body Obesity and Hyperinsulinemia Are Associated with Anovulation. Gynecologic and Obstetric Investigation, 47, 1-5. http://dx.doi.org/10.1159/000010052

[8] Wass, P., Waldenstrom, U., Rossner, S. and Hellberg, D. (1997) An Android Body Fat Distribution in Females Impairs the Pregnancy Rate of In-Vitro Fertilization-Embryo Transfer. Human Reproduction, 12, 2057-2060. http://dx.doi.org/10.1093/humrep/12.9.2057

[9] Lassek, W. and Gaulin, S. (2008) Waist-Hip Ratio and Cognitive Ability: Is Gluteofemoral Fat a Privileged Store of Neurodevelopmental Resources? Evolution and Human Behavior, 29, 26-34. http://dx.doi.org/10.1016/j.evolhumbehav.2007.07.005

[10] de Ridder, C.M., Bruning, P.F., Zonderland, M.L., Thijssen, J.H., Bonfrer, J.M., Blankenstein, M.A., et al. (1990) Body Fat Mass, Body Fat Distribution, and Plasma Hormones in Early Puberty in Females. The Journal of Clinical Endocrinology and Metabolism, 70, 888-893. http://dx.doi.org/10.1210/jcem-70-4-888

[11] de Ridder, C.M., Thijssen, J.H., Bruning, P.F., Van den Brande, J.L., Zonderland, M.L. and Erich, W.B. (1992) Body Fat Mass, Body Fat Distribution, and Pubertal Development: A Longitudinal Study of Physical and Hormonal Sexual Maturation of Girls. The Journal of Clinical Endocrinology and Metabolism, 75, 442-446. http://doi.org/10.1210/jcem.75.2.1639945

[12] Hartz, A., Grubb, B. and Wild, R. (1990) The Association of Waist Hip Ratio and Angiographically Determined Coronary Artery Disease. International Journal of Obesity, 14, 657-665.

[13] Dobbelsteyn, C.J., Joffres, M.R., MacLean, D.R. and Flowerdew, G. (2001) A Comparative Evaluation of Waist Circumference, Waist-to-Hip Ratio and Body Mass Index as Indicators of Cardiovascular Risk Factors. The Canadian Heart Health Surveys. International Journal of Obesity and Related Metabolic Disorders: Journal of the International Association for the Study of Obesity, 25, 652-661. http://doi.org/10.1038/sj.ijo.0801582

[14] Kissebah, A. and Krakower, G. (1994) Regional Adiposity and Morbidity. Physiological Reviews, 74, 761-811.

[15] Hartz, A., Rupley, D. and Rimm, A. (1984) The Association of Girth Measurements with Disease in 32,856 Women. American Journal of Epidemiology, 119, 71-80.

[16] Nelson, T. and Vogler, G. (1999) Genetic and Environmental Influences on Waist-to-Hip Ratio and Waist Circumference in an Older Swedish Twin Population. International Journal of Obesity, 23, 449-455. http://dx.doi.org/10.1038/sj.ijo.0800840

[17] Brewer, C.J. and Balen, A.H. (2010) The Adverse Effects of Obesity on Conception and Implantation. Reproduction, 140, 347-364. http://doi.org/10.1530/REP-09-0568

[18] Manson, J.E., Willett, W.C., Stampfer, M.J., Colditz, G.A., Hunter, D.J., Hankinson, S.E., et al. (1995) Body Weight and Mortality among Women. New England Journal of Medicine, 333, 677-685. http://dx.doi.org/10.1056/NEJM199509143331101

[19] Singh, D. (2006) Universal Allure of the Hourglass Figure: An Evolutionary Theory of Female Physical Attractiveness. Clinics in Plastic Surgery, 33, 359-370. http://dx.doi.org/10.1016/j.cps.2006.05.007

[20] Furnham, A., Moutafi, J. and Baguma, P. (2002) A Cross-Cultural Study on the Role of Weight and Waist-to-Hip Ratio on Female Attractiveness. Personality and Individual Differences, 32, 729-745. http://dx.doi.org/10.1016/S0191-8869(01)00073-3

[21] Yu, D.W. and Shepard, G.H. (1998) Is Beauty in the Eye of the Beholder? Nature, 396, 321-322. http://doi.org/10.1038/24512

[22] Wetsman, A. and Marlowe, F. (1999) How Universal Are Preferences for Female Waist-to-Hip Ratios? Evidence from the Hadza of Tanzania. Evolution and Human Behavior, 20, 219-228. http://dx.doi.org/10.1016/S1090-5138(99)00007-0

[23] Marlowe, F. and Wetsman, A. (2001) Preferred Waist-to-Hip Ratio and Ecology. Personality and Individual Differences, 30, 481-489. http://dx.doi.org/10.1016/S0191-8869(00)00039-8

[24] Swami, V., Knight, D., Tovée, M., Davies, P. and Furnham, A. (2007) Preferences for Female Body Size in Britain and the South Pacific. Body Image, 4, 219-223. http://dx.doi.org/10.1016/j.bodyim.2007.01.002

[25] Swami, V., Jones, J., Einon, D. and Furnham, A. (2009) Men’s Preferences for Women’s Profile Waist-to-Hip Ratio, Breast Size, and Ethnic Group in Britain and South Africa. British Journal of Psychology, 100, 313-325. http://doi.org/10.1348/000712608X329525 
[26] Swami, V. and Tovée, M. (2005) Female Physical Attractiveness in Britain and Malaysia: A Cross-Cultural Study. Body Image, 2, 115-128. http://dx.doi.org/10.1016/j.bodyim.2005.02.002

[27] Tovée, M., Swami, V., Furnham, A. and Mangalparsad, R. (2006) Changing Perceptions of Attractiveness as Observers Are Exposed to a Different Culture. Evolution and Human Behaviour, 27, 443-456. http://doi.org/10.1016/j.evolhumbehav.2006.05.004

[28] Swami, V. and Tovée, M. (2007) Differences in Attractiveness Preferences between Observers in Low- and HighResource Environments in Thailand. Journal of Evolutionary Psychology, 5, 149-160. http://dx.doi.org/10.1556/JEP.2007.1005

[29] Swami, V. and Tovée, M. (2006) Does Hunger Influence Judgments of Female Physical Attractiveness? British Journal of Psychology, 97, 353-363. http://dx.doi.org/10.1348/000712605X80713

[30] Swami, V. (2008) The Influence of Body Weight and Shape in Determining Female and Male Physical Attractiveness. Advances in Psychology Research, 55, 195-220.

[31] Gangestad, S.W. and Scheyd, G.J. (2005) The Evolution of Human Physical Attractiveness. Annual Review of Anthropology, 34, 523-548. http://doi.org/10.1146/annurev.anthro.33.070203.143733

[32] Sugiyama, L. (2004) Is Beauty in the Context-Sensitive Adaptations of the Beholder? Shiwiar Use of Waist-to-Hip Ratio in Assessments of Female Mate Value. Evolution and Human Behaviour, 25, 51-62. http://dx.doi.org/10.1016/S1090-5138(03)00083-7

[33] Cashdan, E. (2008) Waist-to-Hip Ratio across Cultures: Trade-Offs between Androgen- and Estrogen-Dependent Traits. Current Anthropology, 49, 1099-1107. http://doi.org/10.1086/593036

[34] Law Smith, M.J. and Deady, D.K. (2004) Changing Male Preferences for Female Body Type: An Adaptive Response to a Changing Socioeconomic Climate? Proceedings of the Human Behavior and Evolution Society Annual Conference, Berlin, 21-25 July 2004, 43.

[35] Bureau of Labor Statistics, US Department of Labor (2015) http://www.dol.gov/wb/stats/facts_over_time.htm.

[36] Wang, W., Parker, K. and Taylor, P. (2013) Breadwinner Moms: Mothers Are the Sole or Primary Provider in Four-inTen Households with Children-Public Conflicted about the Growing Trend. Pew Research Centre, Washington DC.

[37] Croix, D.D. and Docquier, F. (2003) Changing Returns to Skill and Experience in France and the US: A General Equilibrium Approach. Mimeo, CORE Univ. Catholique de Louvain and CADRE, Univ. Lille 2.

[38] Lawson, D.W. and Mace, R. (2011) Parental Investment and the Optimization of Human Family Size. Philosophical Transactions of the Royal Society of London. Series B, Biological Sciences, 366, 333-343. http://doi.org/10.1098/rstb.2010.0297

[39] Katzmarzyk, P. and Davis, C. (2001) Short Communication: Thinness and Body Shape of Playboy Centerfolds from 1978 to 1998. International Journal of Obesity, 25, 590-592. http://dx.doi.org/10.1038/sj.ijo.0801571

[40] Morris, A., Cooper, T. and Cooper, P. (1989) The Changing Shape of Female Fashion Models. International Journal of Eating Disorders, 8, 593-596. http://dx.doi.org/10.1002/1098-108X(198909)8:5<593::AID-EAT2260080511>3.0.CO;2-H

[41] Garner, D. and Garfinkel, P. (1980) Cultural Expectations of Thinness in Women. Psychological Reports, 47, $483-491$. http://dx.doi.org/10.2466/pr0.1980.47.2.483

[42] Mazur, A. (1986) US Trends in Feminine Beauty and Overadaptation. Journal of Sex Research, 22, 281-303. http://dx.doi.org/10.1080/00224498609551309

[43] Freese, J. and Meland, S. (2002) Seven Tenths Incorrect: Heterogeneity and Change in the Waist-to-Hip Ratios of Playboy Centerfold Models and Miss America Pageant Winners. Journal of Sex Research, 39, 133-138. http://dx.doi.org/10.1080/00224490209552132

[44] Voracek, M. and Fisher, M.L. (2002) Shapely Centrefolds? Temporal Change in Body Measures: Trend Analysis. BMJ, 325, 1447-1448. http://doi.org/10.1136/bmj.325.7378.1447

[45] Vanderschueren, D., Vandenput, L., Boonen, S., Lindberg, M.K., Bouillon, R. and Ohlsson, C. (2004) Androgens and Bone. Endocrinology Reviews, 25, 389-425. http://dx.doi.org/10.1210/er.2003-0003

[46] Orwoll, E.S. (1996) Androgens as Anabolic Agents for Bone. Trends in Endocrinology \& Metabolism, 7, 77-84. http://dx.doi.org/10.1016/1043-2760(96)00024-0

[47] Kasra, M. and Grynpas, M.D. (1995) The Effects of Androgens on the Mechanical Properties of Primate Bone. Bone, 17, 265-270. http://dx.doi.org/10.1016/8756-3282(95)00211-U

[48] Deady, D.K. and Law Smith, M.J. (2006) Height in Women Predicts Maternal Tendencies and Career Orientation. Personality and Individual Differences, 40, 17-25. http://doi.org/10.1016/j.paid.2005.06.014

[49] Ogden, C.L., Fryar, C.D., Carroll, M.D. and Flegal, K.M. (2004) Mean Body Weight, Height, and Body Mass Index, 
United States 1960-2002. Advance Data from Vital and Health Statistics, No. 347.

[50] Deady, D.K., Law Smith, M.J., Sharp, M.A. and Al-Dujaili, E.A.S. (2006) Maternal Personality and Reproductive Ambition in Women Is Associated with Salivary Testosterone Levels. Biological Psychology, 71, $29-32$. http://dx.doi.org/10.1016/j.biopsycho.2005.01.009

[51] Law Smith, M.J., Deady, D.K., Sharp, M.A. and Al-Dujaili, E.A.S. (2013) Sex-Role Orientation in Men Is Related to Salivary Testosterone Levels. Journal of Behavioral and Brain Science, 3, 518-521. http://doi.org/10.4236/jbbs.2013.37054

[52] Law Smith, M.J., Deady, D.K., Moore, F.R., Jones, B.C., Cornwell, R.E., Stirrat, M., et al. (2012) Maternal Tendencies in Women Are Associated with Estrogen Levels and Facial Femininity. Hormones and Behaviour, 61, 12-16. http://dx.doi.org/10.1016/j.yhbeh.2011.09.005

[53] Chu, S. and Geary, K. (2005) Physical Stature Influences Character Perception in Women. Personality and Individual Differences, 38, 1927-1934. http://dx.doi.org/10.1016/j.paid.2004.10.004 